\title{
Anxious times
}

\author{
Photovoltaics and LED lighting look set to ride out the economic downturn, but a spate of consolidation \\ in other sectors is likely as markets decline in 2009.
}

It certainly looks like the photonics sector is going to have a bumpy ride in 2009, judging from recent indicators. As our commentary article on page 67 reports, the share prices of many well-known photonics companies have plummeted over the past 12 months, and on paper many firms now have values of around half or one-third of what they were in January 2008. As consumer spending around the world reduces, laser technology which is integral to many manufacturing processes spanning from the production of semiconductor chips to welding of car bodies is being hit. Indeed, an annual market report published last month by the trade magazine Laser Focus World (www.laserfocusworld.com) predicts that sales of all types of laser will fall at least $11 \%$ year-on-year in 2009 . In contrast, last year there was a $3.7 \%$ rise in sales to reach US\$7.1 billion, and in recent years growth has typically been in double digits.

Even the display sector, which has been a particularly buoyant and lucrative market in recent years for many photonics firms, especially the US glass manufacturer Corning, seems to be faltering as overcapacity, intense competition and a reduction in sales of LCD-televisions, monitors and computer laptops start to have an impact. According to the market analyst firm, DisplaySearch (www.displaysearch. com), shipments of large thin-film transistor LCDs fell 21\% month-on-month in November 2008 with revenue declining to US $\$ 3.8$ billion, the lowest value since mid-2006.

And while the downturn triggers severe falls in share-prices, profit warnings, hiringfreezes and redundancies in large public companies, it is also affecting the small, start-up firms that are struggling to find investment funding as venture capitalists zip their wallets shut. Although it is still early days for the full effects of the recession to be seen, it is likely that down the road the result will be a reduction in the number of new photonics companies getting off the ground, a reduction in initial public offerings (IPOs) and a bout of market consolidation, associated with a significant rise in the number of mergers and acquisitions. Indeed, over the past six months there have already been signs that the latter has started in the laser materials processing

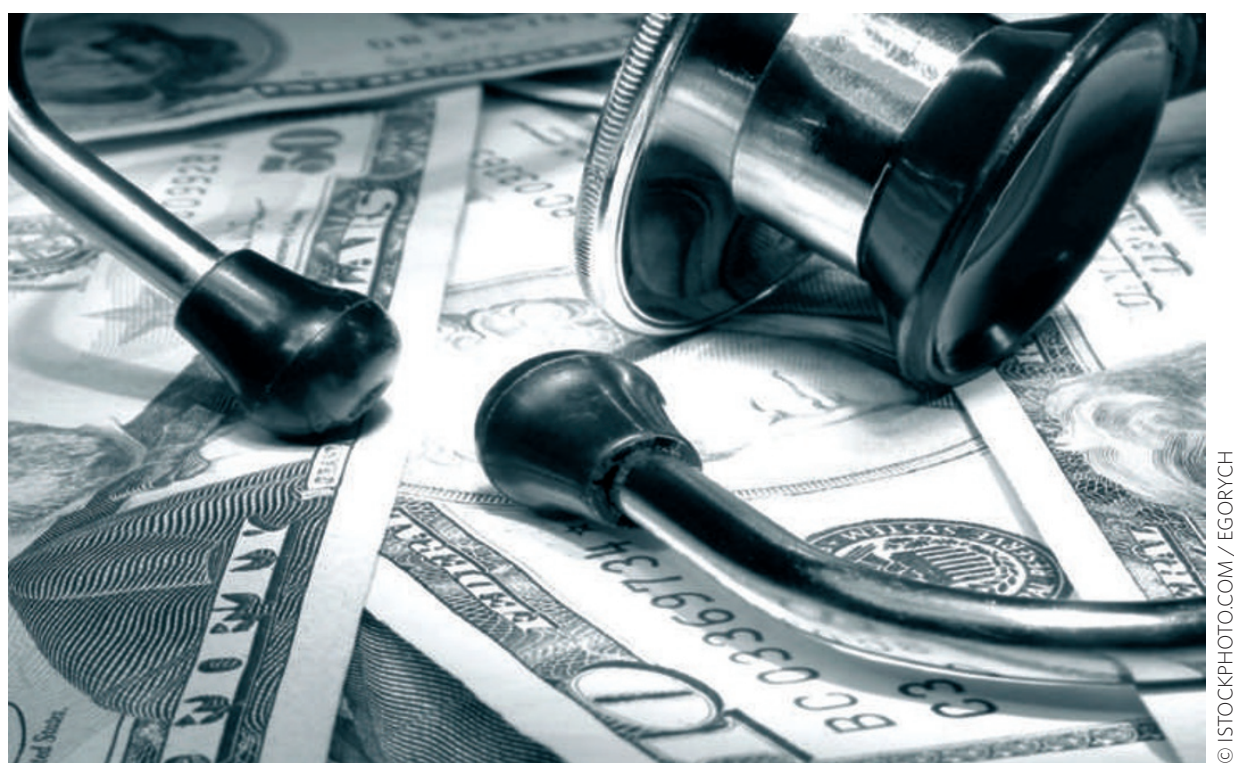

market, with the German giant of industrial lasers TRUMPF purchasing SPI Lasers, GSI Lumonics purchasing Excel Technology, and Lockheed Martin buying Aculight. No doubt there are many more deals coming.

\section{The photonics sector is in}

\section{for a bumpy ride in 2009.}

However, it's not all doom and gloom, and it is important to keep a balanced perspective on how the state of the world economy is affecting photonics. It should not be forgotten that one of the great strengths of photonics is its diversity, and as a result there are some sectors that will continue to thrive and prosper despite the downturn. The two sectors that seem best positioned to ride out the storm are closely related to energy generation and energy saving photovoltaics and solid-state (LED) lighting.

Concerns over the long-term price and availability of oil, a desire to make use of environmentally friendly technologies and steady improvements in photovoltaic technologies have made solar energy a strategic, long-term investment for many power generation firms. Manufacturers of photovoltaic panels, such as Sharp, Q-cells and Suntech, are reaping the benefits. Indeed, a recent report by Nanomarkets (www.nanomarkets.net) predicts that the revenue from photovoltaics will continue to grow to hit US\$2.4 billion in 2011 and around US $\$ 7.5$ billion in 2015 . The sector has also received support from the new United States president Barack Obama who says that it is his intention to double the production of alternative energy in the next three years and improve the energy efficiency of American homes.

The other sector expected to grow despite difficult times is that of LED lighting. Thanks to steady improvements in the yield, brightness and efficiency of white LEDs, they are starting to become a viable and attractive alterative to other forms of lighting. LEDs have now been packaged into lamp housings that are compatible with standard bulb fittings, allowing a backwards-compatible 'fit and forget' solution for the home. Deployment of LEDs in cars and electronic items has become commonplace, and it now seems that the residential lighting market is at a tipping point. Indeed, the news that the European Union has recently declared a ban on incandescent lighting that will start in 2010 is likely to help boost the sector, and mean that all household lighting in the EU will become either LED or fluorescent.

The big question that nobody can easily answer is how long this recession will last. We, like everyone else, will certainly be hoping that a recovery comes sooner rather than later. 